УДК 504.064.2:502.057:57.025:574.24:519.876

ЗАКОНОМЕРНОСТИ ДИНАМИКИ СРЕДНЕЙ ШИРИНЫ ЛИСТЬЕВ БЕРЕЗЫ ПОВИСЛОЙ ОКОЛО МАКСИМУМА РОСТА В ВЕГЕТАЦИОННЫЙ ПЕРИОД

\author{
Мазуркин П.М., Кудряшова А.И.
}

Поволжский государственный технологический университет, Йошкар-Ола, e-mail:kaf_po@mail.ru,Little-one7@yandex.ru

\begin{abstract}
Показано, что достижение максимума средней ширины учетных листьев березы повислой (Betula pendula) становится великолепным биоиндикатором качества окружающей дерево среды. Причем оценку качества можно проводить без измерений концентрации загрязнений. По основному патенту 2606189 с изменениями на новое изобретение, сбоку на высоте 1,5-2,0 м со стороны преобладающих ветров по динамике с 27 июля по 23 сентября 2018 г. измерялись средняя ширина 10 учетных листьев у березы, расположенной около автомобильной дороги. Параметры устойчивой модели с двумя составляющими показали, что полупериод колебания в начале вегетационного периода для 10 берез изменяется от 1,32 до 21,35 суток. При этом максимум ширины у каждого дерева березы изменяется, и он достигается в разные даты. Все модели динамики одинаковы по конструкции, но имеют разный характер изменения по параметрам. Время вегетации около максимума роста влияет с коэффициентом корреляции более 0,999 , поэтому поведение 10 листьев в ходе их роста и развития имеет высокую квантовую определенность. Для оценки поведения таких групп листьев введен новый критерий - коэффициент динамичности, равный отношению разницы между фактом по измерениям и трендом к фактическим значениям средней ширины учетных листьев березы повислой. Максимумы ширины листьев дали и наибольшие значения коэффициента динамичности. Этот критерий позволяет ранжировать березы по убыванию влияния колебаний от влияния окружающей эти березы среды. Получены закономерности.
\end{abstract}

Ключевые слова: вегетация, преобладающие ветра, 10 берез, 10 учетных листьев, ширина, динамика, колебательная адаптация, коэффициент динамичности, закономерности

\title{
REGULARITIES OF THE DYNAMICS OF THE AVERAGE WIDTH OF THE LEAVES OF SILVER BIRCH NEAR THE MAXIMUM GROWTH IN THE VEGETATION PERIOD
}

\author{
Mazurkin P.M., Kudryashova A.I.
}

Volga State University of Technology,Yoshkar-Ola,e-mail:kaf_po@mail.ru,Little-one7@yandex.ru

\begin{abstract}
It is shown that the achievement of the maximum of the average width of the birch leaves is a great bioindicator of environmental quality. Moreover, the quality assessment can be carried out without measuring the concentration of pollution. According to patent 2606189 for the invention on the side at an altitude of $1.5-2.0 \mathrm{~m}$ from the prevailing winds on the dynamics from July 27 to September 23, 2018, the average width of 10 leaves near the road was measured. The parameters of the model with two components showed that the half-period of oscillation at the beginning of the growing season for 10 birches varies from 1.32 to 21.35 days. All models of dynamics are the same in design, but have a different character. The growing season near the maximum growth affects with a correlation coefficient of more than 0.999 , so the behavior of 10 leaves has a high quantum certainty. To assess the behavior of groups of leaves, a new criterion was introduced - the coefficient of dynamism equal to the ratio of the difference between the fact and the trend to the fact of the average width of the leaves of the birch. The maximum width of the leaves and gave the highest values of the coefficient of dynamism. This criterion allows to rank the birch in descending order of the influence of vibrations from affecting the surrounding of the birch environment.
\end{abstract}

Keywords: vegetation, prevailing winds, 10 birch, 10 account of leaves, width, dynamics, oscillatory adaptation, the dynamic factor, patterns

Эволюция климата Земли на геологические сроки в значительной степени обусловлена вариациями суммарной солнечной радиации [1] и изменениями в содержании парниковых газов в атмосфере. Изменения климата влияют на растительность [2].

Расширение наземных растений вместе с океаном позволило обеспечить долговременную обитаемость на планете. Человечество использует ископаемые виды топлива, к середине XXI в. значения $\mathrm{CO}_{2}$ будет одинаковы с ранним эоценом (50 млн лет назад). Если концентрация $\mathrm{CO}_{2}$ продолжит расти и в XXIII в., земля будет реагировать как за полтора миллиарда лет [3].
Понимание реакции растений на факторы окружающей среды необходимо для прогнозирования изменений темпов поглощения углерода в лесах при различных условиях окружающей среды. В Финляндии имеется представление о реакции молодых лиственных деревьев на повышение температуры воздуха во взаимодействии с тропосферным озоном. Эти знания повышают шансы на разработку моделей для включения параметров, которые описывают лесную систему в изменяющихся климатических условиях [4]. Можно утверждать, что будущее сдерживания количества $\mathrm{CO}_{2}$ находится в увеличении площади лесов $[5,6]$. 
Динамику температуры [7] можно описать множеством асимметричных вейвлетов (множеством квантов поведения) вплоть до ошибки измерений. Аналогично хорошо квантуется содержание $\mathrm{CO}_{2}$ в атмосфере. По вейвлетам универсальной конструкции изменяется динамика углерода в Европе [8].

Рост растений - сложный процесс, в его основе лежат такие фундаментальные явления, как ритмичность, полярность, дифференциация, раздражимость, корреляция. Эти процессы являются общими для онтогенеза живых организмов. Онтогенез - индивидуальное развитие организма от зиготы (или вегетативного зачатка) до природной смерти. Благодаря активной деятельности меристем и фотосинтетической активности листьев зеленое растение приобретает ряд черт, которые характеризуют его рост. В процессе онтогенеза растения рост наблюдается на протяжении основных этапов его жизненного цикла [9-11]. Поэтому в дальнейших исследованиях можно выявлять закономерности влияния метеорологических параметров на динамику вегетативных органов растений.

В экологических технологиях с использованием листьев березы повислой постепенно приходит понимание необходимости моделирования взаимных связей между параметрами структуры листьев растений методом идентификации [12]. Это изобретение относится к инженерной биологии и биоиндикации окружающей среды измерениями качества ростовых органов различных видов растений, преимущественно древесных растений, например проб в виде листьев берез без их срезания с простой и небольшой листовой пластинкой.

Цель статьи: повышение точности индикации качества окружающей листья березы локальной среды по патенту 2606189 на изобретение сбоку на высоте 1,5-2,0 м со стороны преобладающих ветров по динамике с 15 июля по 23 сентября 2018 г. средней ширины 10 учетных листьев около автомобильной дороги с интенсивным движением.

\section{Материалы и методы исследования}

В табл. 1 приведены средние ширины для 10 учетных листьев, принятых без срезания и измеренные с 27 июля по 23 сентября 2018 г. Всего получилось 18 строк. Первая точка 01 мая в 2018 г. оказалась началом вегетационного периода, поэтому ставим 0 .
Колебания, в частности и тренды, записываются волновой формулой [12] вида

$$
\begin{gathered}
y_{i}=A_{i} \cos \left(\pi x / p_{i}-a_{8 i}\right), \\
A_{i}=a_{1 i} x^{a_{2 i}} \exp \left(-a_{3 i} x^{a_{4 i}}\right), \\
p_{i}=a_{5 i}+a_{6 i} x^{a_{7 i}},
\end{gathered}
$$

где $y$ - показатель (зависимый фактор), $i-$ номер составляющей модели $(*), m$ - количество членов в модели $(*), x$ - объясняющая переменная (влияющий фактор), $a_{1} \ldots$ $a_{8}$ - параметры модели (*), принимающие числовые значения в ходе структурно-параметрической идентификации в программной среде CurveExpert-1.40, $A_{i}$ - амплитуда (половина) вейвлета (ось $y$ ), $p_{i}$ - полупериод колебания (ось $x$ ).

Мы исключаем меру значимости $0,05 \%$ [13] и оцениваем адекватность формул по коэффициенту корреляции. Все 10 статистических моделей получились с адекватностью выше 0,999. Поэтому динамика роста и спада листьев имеет высокую квантовую определенность.

\section{Результаты исследования и их обсуждение}

В табл. 2 приведены параметры модели (*) с двумя составляющими, первый из которых является трендом в виде биотехнического закона [12]. Цикличность колебания на 01.05.2018 г. в виде полупериода показывает параметр $a_{5 i}$. Полупериод колебания в начале вегетационного периода для 10 берез изменяется от 1,32 (ул. Панфилова) до 21,35 суток (ул. Лебедева).

На рис. 1 и 2 приведены графики двухчленных формул по данным табл. 2. Все они одинаковы по конструкции, но имеют разный характер изменения во времени. Тогда можно утверждать, что динамика параметров листьев березы повислой в период вегетации около максимума приращения является очень высокоадекватной с коэффициентом корреляции более 0,999 , то есть среднее поведение 10 учетных листьев имеет квантовую определенность. Но метеопараметры за период вегетации березы повислой имеют сильную квантовую запутанность. Тогда в дальнейшем необходимо понять, как же листья березы за 180 млн лет эволюции получили такую высокую колебательную адаптивность? Такое чувство, будто бы они понимают и ведут своими вегетативными органами осознанно к изменениям в окружающей группу учетных листьев среде. 
5

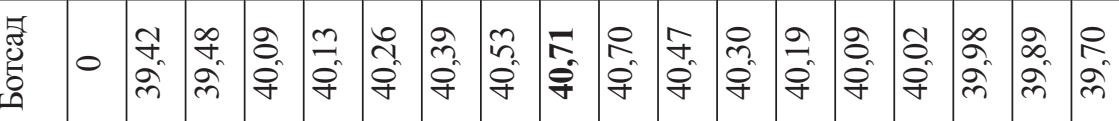

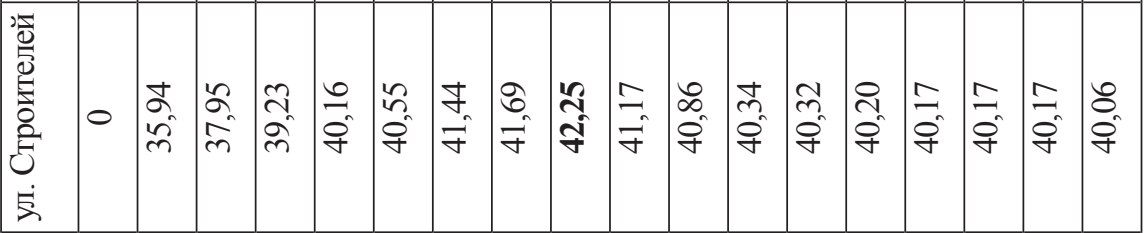

苟



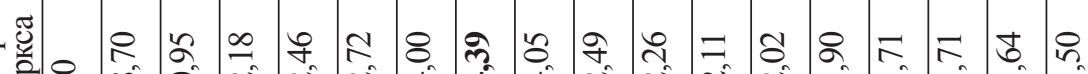

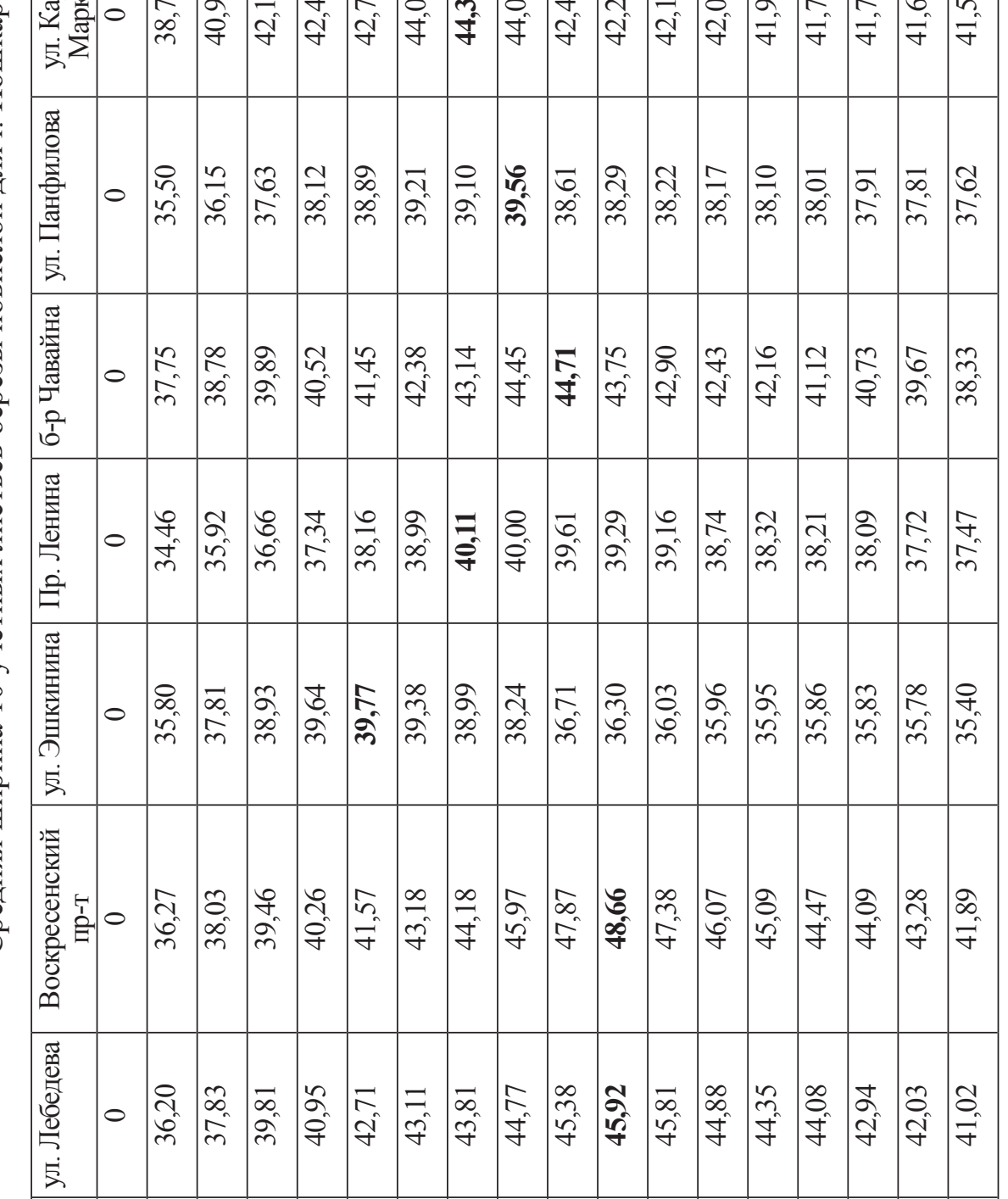

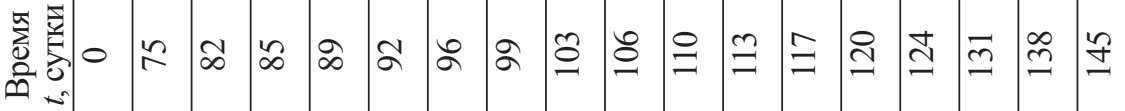

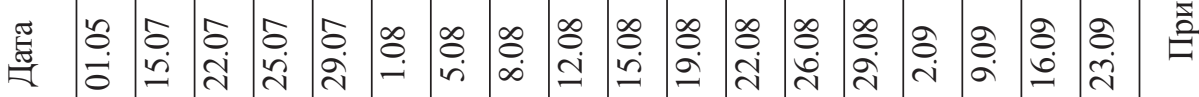




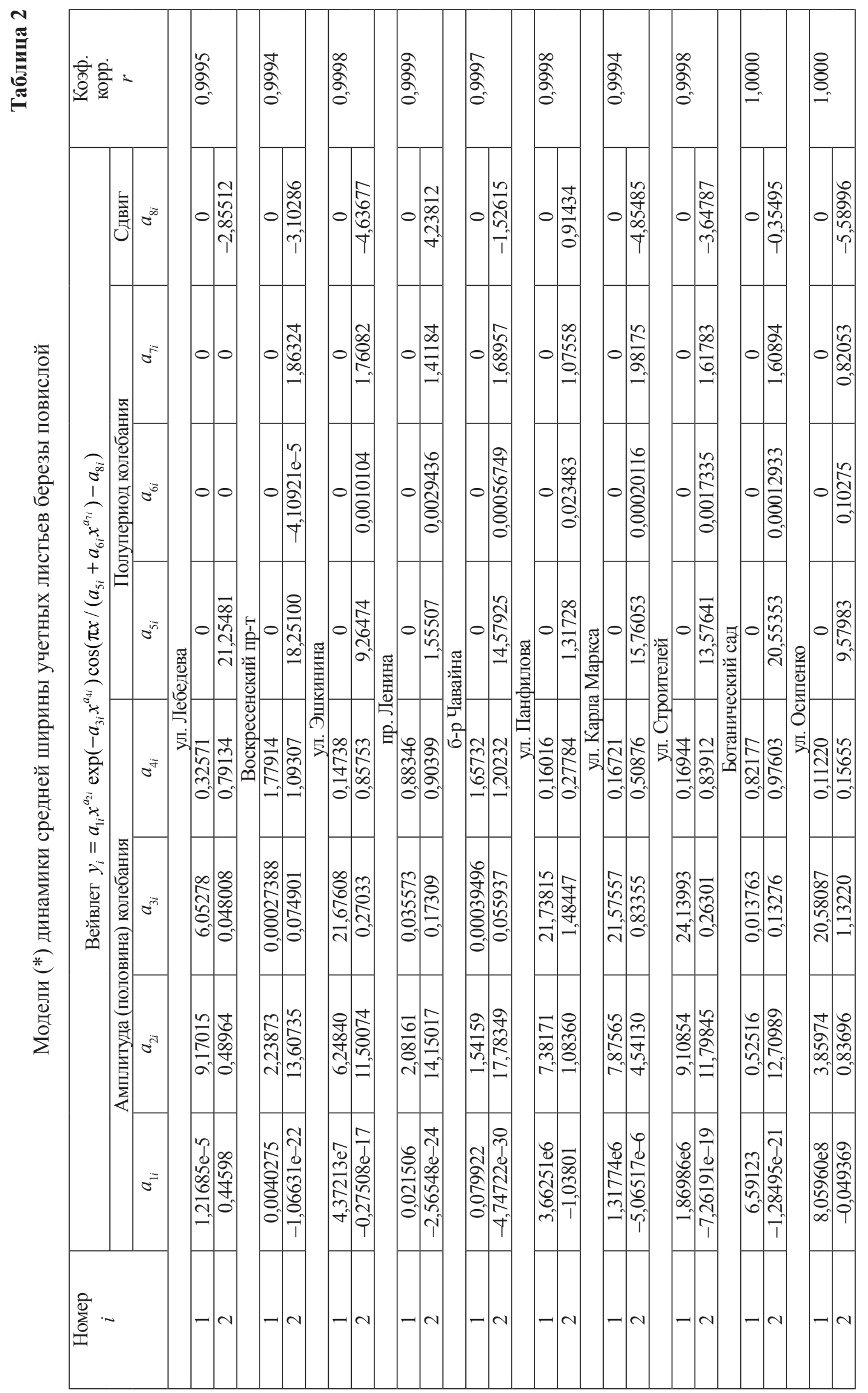




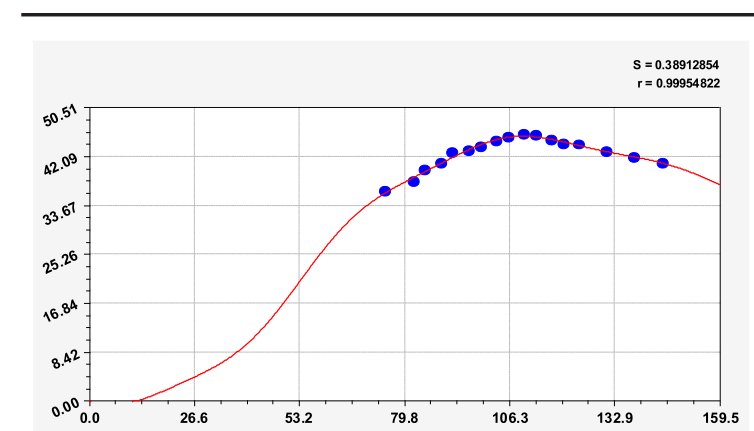

ул. Лебедева

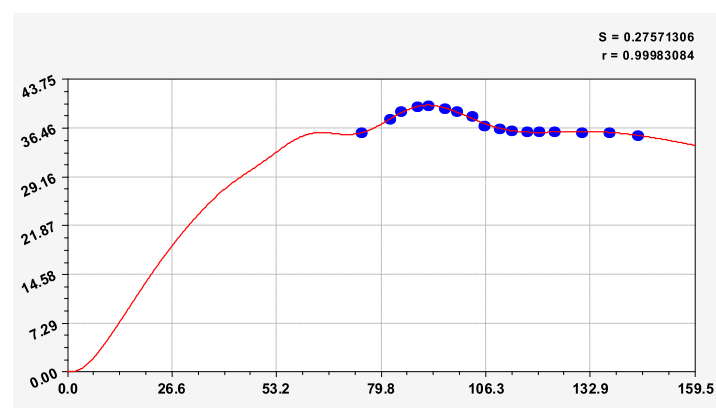

ул. Эикинина

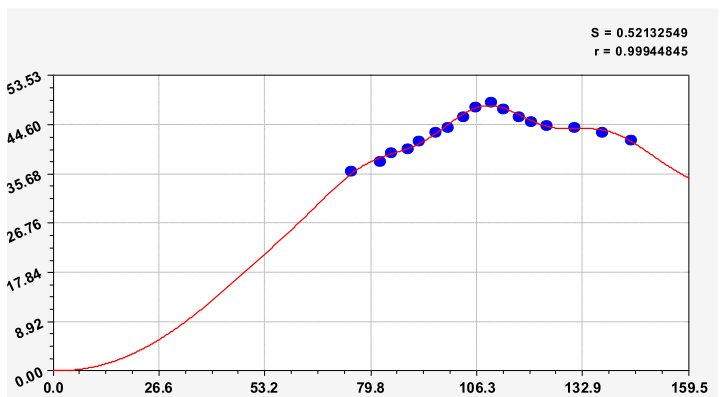

Воскресенский пр-т

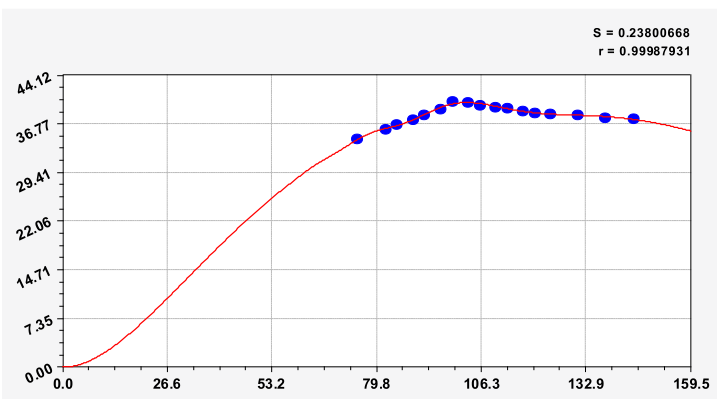

пр. Ленина

Рис. 1. Графики динамики средней ширины группы из 10 учетных листьев березы повислой

Для оценки поведения групп листьев введем новый критерий - коэффициент динамичности, равный отношению разницы между фактом и трендом к факту средней ширины (табл. 3). Максимумы ширины листьев дали и наибольшие значения коэффициента динамичности.

Этот критерий позволяет ранжировать березы по убыванию влияния колебаний.

По табл. 3 места по ухудшению условий распределяются так: 1) 0,0072 - ул. Осипенко, на которой почти нет автомашин; 2) 0,0073 - ботанический сад, очень малое влияние забора вокруг объекта; 3) 0,0189ул. Панфилова; 4) 0,0198 - ул. Лебедева; 5) 0,0270 - проспект Ленина; 6) 0,0275 ул. Строителей; 7) 0,0327 - проспект Карла Маркса; 8) 0,0438 - бульвар Чавайна; 9) 0,0431 - ул. Эшкинина; 10) 0,0487 - Воскресенский проспект.

Так что же лучше: спокойная жизнь при низком коэффициенте динамичности или же наибольшее приращение средней ширины учетных листьев березы повислой? По средней максимальной ширине листа из табл. 1 березы по ухудшению продуктивности расположились так: 1) 48,66 мм - Воскресенский проспект; 2) 45,92 мм - ул. Лебедева; 3) 44,71 мм - бульвар Чавайна; 4) 44,39 мм ул. Карла Маркса; 5) 44,09 мм - ул. Осипенко; 6) 42,25 мм - ул. Строителей; 7) 40,71 мм - ботанический сад; 8) 40,11 мм проспект Ленина; 9) 39,77 мм - ул. Эшкинина; 10) 39,56 мм - ул. Панфилова. Конечно же, на скорость приращения и достижение средней максимальной ширины учетных листьев влияет и собственное физиологическое состояние дерева. Например, береза с продуктивными листьями по табл. 1 за четверо суток с 15,08 по 19,08 изменила на Воскресенском проспекте среднюю ширину листьев с 47,87 до 48,66 мм или имела скорость приращения $(48,66$ - 47,87) / $4=$ $=0,198$ мм. А на ул. Панфилова средняя скорость роста ширины листьев равна $(39,56-$ $39,10) / 4=0,115$ мм. 


\begin{tabular}{|c|c|c|c|c|c|c|c|c|c|c|c|c|c|c|c|c|c|c|}
\hline 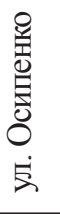 & 1 & \& & 电 & 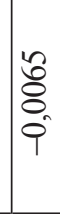 & \&े & 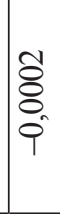 & 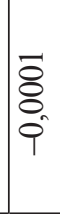 & 尽 & 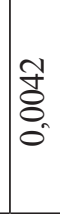 & 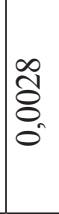 & 命 & $\frac{n}{8}$ & 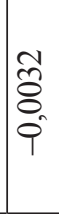 & $\underset{8}{\stackrel{8}{8}}$ & 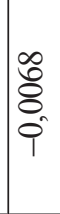 & $\frac{2}{8}$ & of & $\begin{array}{l}\overline{8} \\
8 \\
0 \\
0\end{array}$ \\
\hline 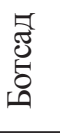 & 1 & 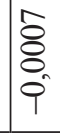 & $\hat{\bar{\theta}}$ & శ్ & 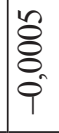 & 令 & $\frac{n}{8}$ & $\begin{array}{l}\infty \\
\tilde{\delta} \\
0 \\
0\end{array}$ & 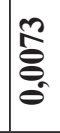 & $\begin{array}{l}\infty \\
\varnothing \\
\delta \\
0 \\
0\end{array}$ & $\frac{m}{8}$ & 苍 & 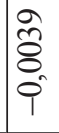 & 令 & 总 & $\frac{n}{8}$ & ס्ञ̄ & 웅 \\
\hline 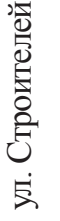 & 1 & $\begin{array}{l}\bar{n} \\
0 \\
0 \\
0\end{array}$ & \& & $\begin{array}{l}\hat{\sigma} \\
\delta \\
0 \\
0\end{array}$ & 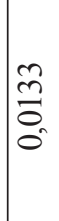 & $\frac{a}{\bar{\sigma}}$ & $\frac{\overline{\bar{\sigma}}}{\delta}$ & 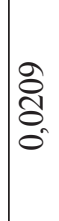 & 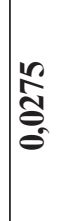 & $\frac{\nabla}{8}$ & $\frac{n}{\vec{\sigma}}$ & ڤે & 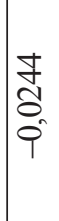 & 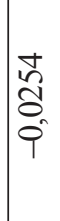 & $\begin{array}{l}\overrightarrow{\widetilde{\Omega}} \\
\stackrel{\S}{\circ}\end{array}$ & $\frac{ \pm}{\bar{\sigma}}$ & $\vec{\delta}$ & $\begin{array}{l}\frac{1}{0} \\
0 \\
0\end{array}$ \\
\hline
\end{tabular}

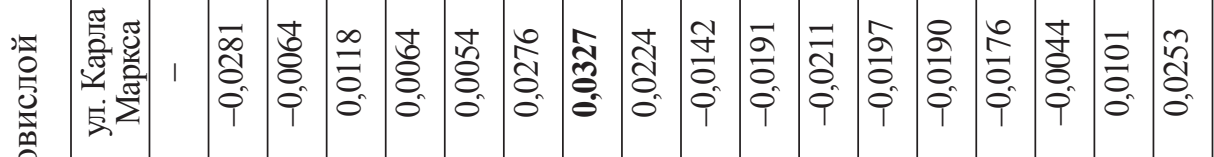

党

$\frac{0}{8}$

(⿻)



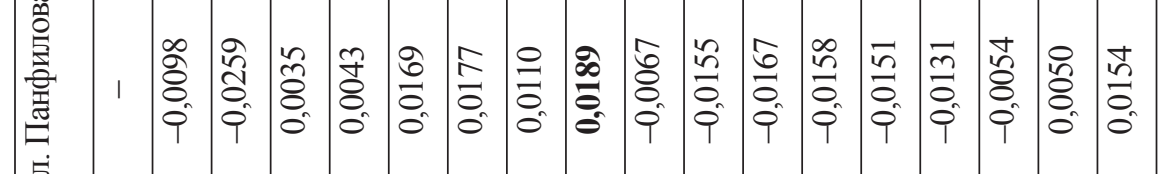

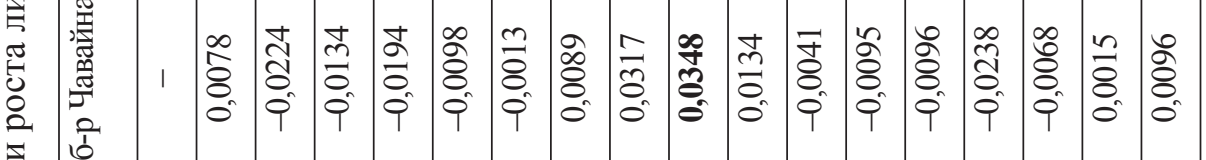

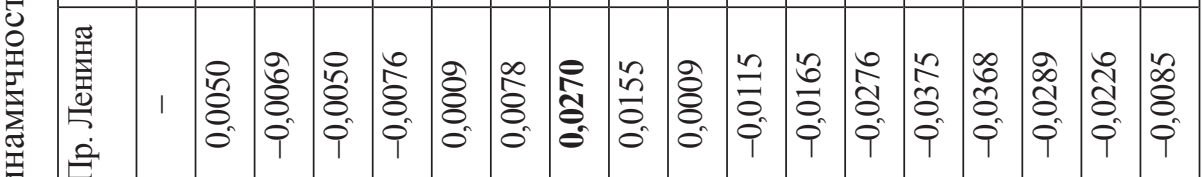

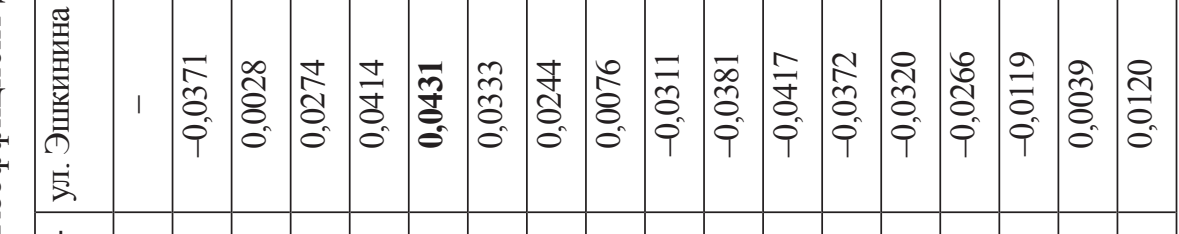

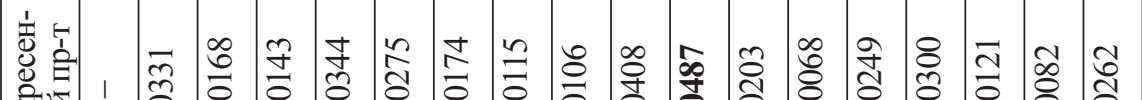

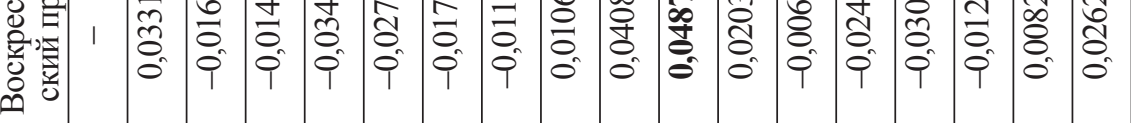

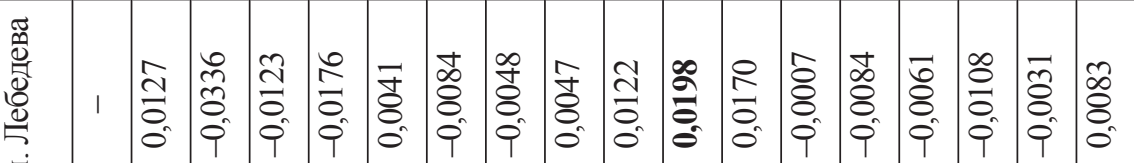

도.

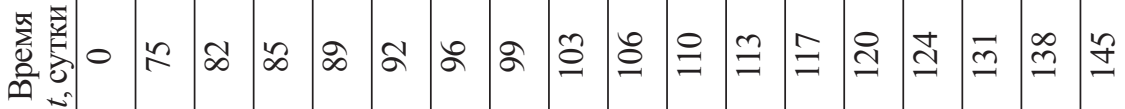

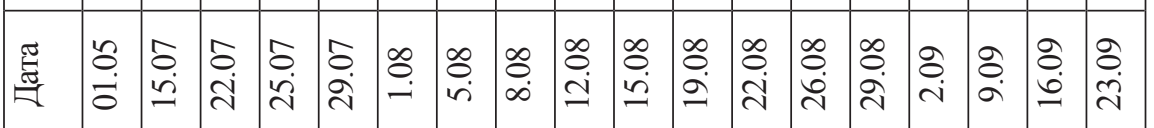

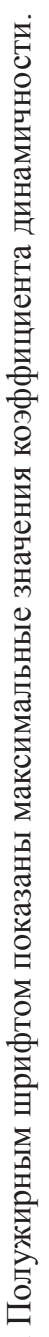




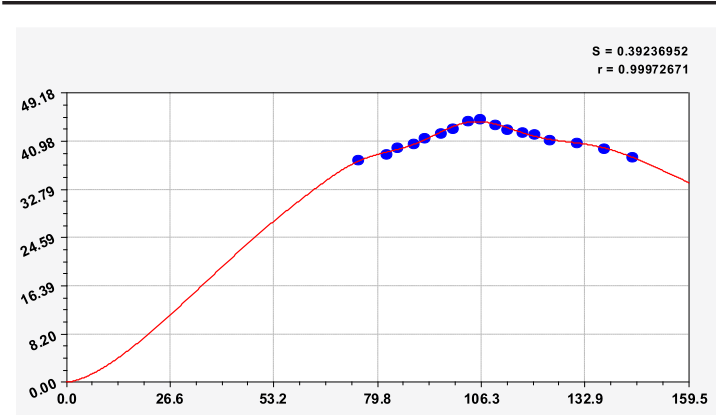

б-р Чавайна

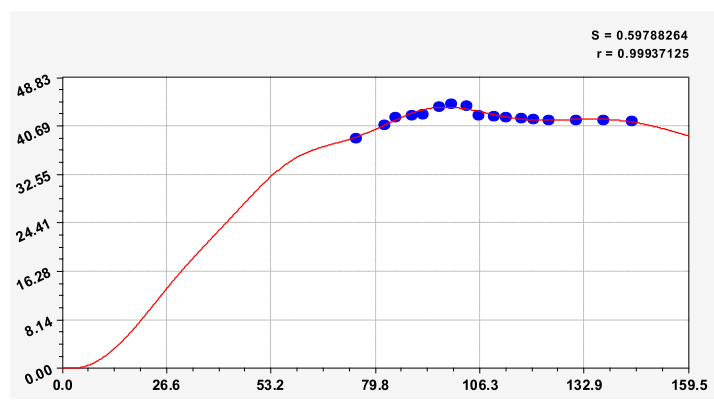

ул. Карла Маркса

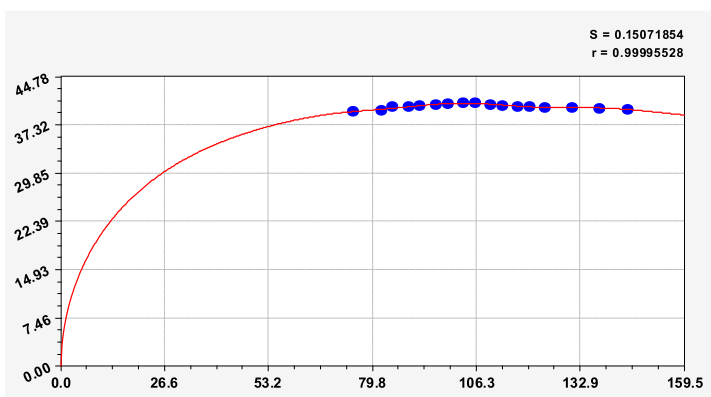

Ботанический сад

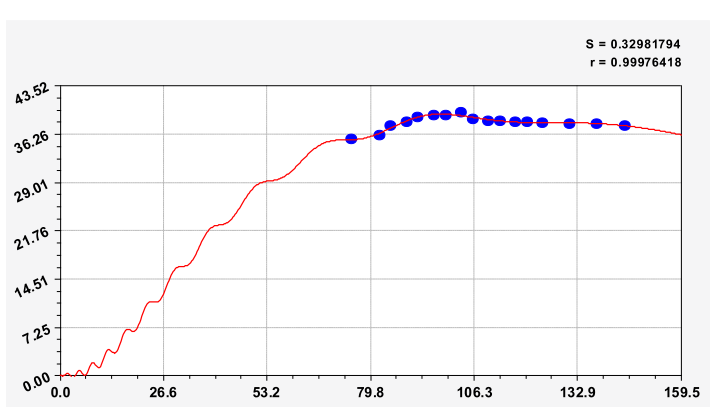

ул. Панфилова

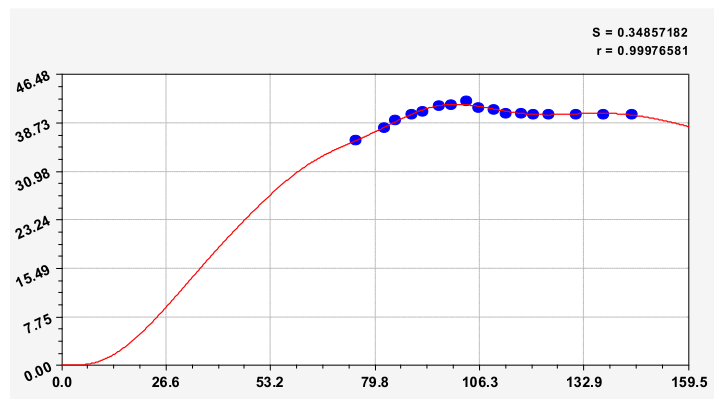

ул. Строителей

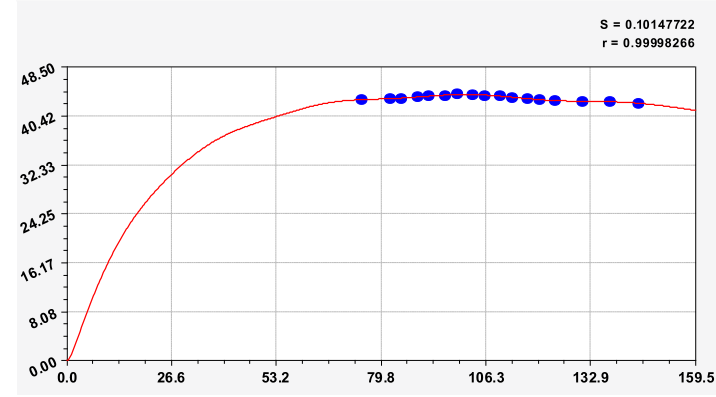

ул. Осипенко

Рис. 2. Графики динамики средней ширины группы из 10 учетных листьев березы повислой

Как известно, мониторинг окружающей среды выполняют по множеству видов загрязнений, содержание которых в воздухе, воде и почве не должно превышать предельно допустимых концентраций. Однако косвенный мониторинг через поведение учетных листьев березы повислой, в вегетационный период позволяет без измерения концентраций загрязнений провести экологическую оценку территории места произрастания данной березы. В итоге листья березы реагируют на все изменения в окружающей березу среде, причем учитывают и те воздей- ствия, которые еще неизвестны человеку. В этом проявляется сущность наших способов индикации окружающей среды, и патент 2606189 становится пионерным решением.

Для принятия за критерии экологической оценки скорости приращения необходимо учитывать еще и физиологические параметры дерева, например классы санитарного состояния, возраст и другое. Таким образом, для индикации среды вокруг березы пока рекомендуется коэффициент динамичности при максимуме средних размеров учетных листьев. 


\section{Заключение}

По патенту 2606189 на изобретение сбоку на высоте 1,5-2,0 м со стороны преобладающих ветров по динамике с 15 июля по 23 сентября 2018 г. измерялись средняя ширина 10 учетных листьев около автомобильной дороги. Параметры модели с двумя составляющими показали, что полупериод колебания в начале вегетационного периода для 10 берез изменяется от 1,32 до 21,35 суток. Все модели динамики одинаковы по конструкции, но имеют разный характер. Время вегетации около максимума роста влияет с коэффициентом корреляции более 0.999, поэтому поведение 10 листьев имеет квантовую определенность.

Для оценки поведения групп листьев введен новый критерий - коэффициент динамичности, равный отношению разницы между фактом и трендом к факту средней ширины. Максимумы ширины листьев дали и наибольшие значения коэффициента динамичности. Этот критерий позволяет ранжировать березы по убыванию влияния колебаний от влияния среды.

Средняя ширина 10 учетных листьев березы повислой показала очень малую погрешность, поэтому количество учетных листьев с одной локальной зоны можно уменьшить до 5. Измерение ширины учетных листьев до достижения максимума роста почти в два раза сокращает промежуток времени для проведения экспериментов. Это позволяет увеличить количество учетных деревьев, произрастающих в разных экологических условиях, а также уменьшить, например до двух суток, промежутки между измерениями. Время измерений в каждый год можно начать с 01 июля и продолжать до 20 августа.

\section{Список литературы / References}

1. Zharkova V. The solar magnet field and the terrestrial climate. [Electronic resource]. URL: https://watchers. news/2018/11/11/valentina-zharkova-solar-magnet-field-andterrestrial-climate-presentation/ (date of access: 01.03.2019).

2. Mazurkin P.M., Kudryashova A.I. Method of measurement of dynamics of growth of leaves of the tree in clean ecological conditions. 18th International Multidisciplinary Scientific GeoConference SGEM 2018. 2018. Vol. 18. Issue 5.1. P. 517-524. DOI: 10.5593/sgem2018/5.1/S20.067.

3. Foster G.L., Royer D.L., Lunt D.J. Future climate forcing potentially without precedent in the last 420 million years. Nature communications. 2017. 8:14845. DOI: 10.1038/ncomms14845.

4. Mdenpp M. Impacts of temperature and ozone on carbon retention processes of birch and aspen Dissertations in Forestry and Natural Sciences. Finland, Joensuu, on June, 08, 2012. 54 p.

5. Crowther T.W., Glick H.B., Covey K.R., Bettigole C., et al. Mapping tree density at a global scale. Nature. 2015. Vol. 525. P. 201-205. DOI:10.1038/nature14967.

6. Büntgen U., Wacker L., Galván J.D., Arnold S., et al. Tree rings reveal globally coherent signature of cosmogenic radiocarbon events in 774 and $993 \mathrm{CE}$. Nature communications. 2018. 9:3605. DOI: 10.1038/s41467-018-06036-0.

7. Mazurkin P.M., Kudryashova A.I. Quantum fitometeorologia: quanta behavior of Meteorological parameters on a three hour Measurements in the vegetation period birch. Journal of Modern Technology and Engineering. 2019. Vol. 4. № 2. P. 72-88.

8. Mazurkin P.M., Kudryashova A.I. Factor analysis of annual global carbon dynamics (according to Global Carbon Budget 2017. Materials of the International Conference «Research transfer»- Reports in English (part 2). November 28, 2018. Beijing, PRC, 2018. P. 192-224.

9. Zhang Y., Bielory L., Georgopoulos P. Climate change effect on Betula (birch) and Quercus (oak) pollen seasons in US. International Journal of Biometeorology. 2014. Vol. 58. № 5. P. 909-919. DOI: 10.1007/s00484-013-0674-7.

10. Polgar C.A., Primack R.B. Leaf-out phenology of temperate woody plants: from trees to ecosystems. New Phytologist. 2011. Vol. 191. P. 926-941. DOI: 10.1111/j.1469-8137.2011.03803.x.

11. Rousi M., Pusenius J. Variations in phenology and growth of European white birch (Betula Pendula) clones. Tree Physiology. 2005. Vol. 25 (2). P. 201-210. DOI: 10.1093/ treephys/25.2.201.

12. Mazurkin P.M. Method of identification. 14th International Multidisciplinary Scientific GeoConference \& EXPO SGEM2014 (SGEM). Albena, Bulgaria, 2014. Vol. 1 (6). P. 427-434.

13. Wasserstein R.L., Schirm A.L., Lazar N.A. Moving to a WorldBeyond $« p<0.05 »$. The American Statistician. 2019. Vol. 73. Issue sup1. P. 1-19. DOI: 10.1080/00031305.2019.1583913. 